\title{
Longitudinal differences in the statistical characteristics of ionospheric spread-F occurrences at midlatitude in Eastern Asia
}

\author{
Ning Wang ${ }^{1,2,3^{*}} \mathbb{D}$, Lixin Guo ${ }^{1}$, Zonghua Ding ${ }^{3}$, Zhenwei Zhao ${ }^{3}$, Zhengwen $X^{3}{ }^{3}$, Tong $X^{3}$ and Yanli $\mathrm{Hu}^{3}$
}

\begin{abstract}
Spread- $\mathrm{F}$ is known as the electron density inhomogeneous structures in $\mathrm{F}$ layer of ionosphere and can usually be classified as frequency spread-F (FSF) and range spread-F (RSF). Few studies have reported on the statistical characteristics of spread-F occurrences at midlatitudes in Eastern Asia, particularly the comparison of spread-F occurrences between China and Japan. In this paper, we used spread- $F$ data recorded by ten ionosondes located between $25^{\circ} \mathrm{N}$ and $45^{\circ} \mathrm{N}$ from 1997 to 2016, to investigate the longitudinal differences in the statistical characteristics of spread-F occurrence and the probable mechanism for its occurrence at midlatitudes in Eastern Asia. Variations in the spread-F occurrences with the solar and geomagnetic activities, season and local time are presented. The main conclusions are as follows: (a) the occurrence percentage of FSF is higher than that of RSF, of which the former is anti-correlated with the solar or geomagnetic activities; (b) higher FSF occurrence percentages mostly appeared during summer, while RSF occurred more frequently in winter near $45^{\circ} \mathrm{N}$ latitude such as Urumqi, Changchun and Wakkanai; (c) the maximum of the FSF occurrence percentages mostly appeared between 01:00 and 02:00 LT approximately, whereas that of RSF appeared near 00:00 LT; (d) the spread-F occurrence percentages in the coastal or marine areas are higher than those in the inland region between $35^{\circ} \mathrm{N}$ and $45^{\circ} \mathrm{N}$ latitudes; however, this phenomenon is not obvious at lower latitudes; and (e) both the mean occurrences of FSF and RSF reach the minimum around $31^{\circ} \mathrm{N}$ latitude. These above results are helpful for understanding variations in spread-F occurrence at midlatitudes in Eastern Asia.
\end{abstract}

Keywords: Spread-F, Occurrence percentages, Longitudinal difference, Acoustic gravity wave, Perkins instability, Eastern Asia

\section{Introduction}

Spread-F has been widely studied since it was first defined on the ionogram in the early 1930s (Booker and Wells 1938). Several observations since then revealed the main morphological features of spread-F occurrence, including its dependences on solar and magnetic activities, season, longitude, latitude, local time and the background ionosphere (Aarons et al. 1980; Abdu et al. 1981, 1983, 1998; Fukao et al. 2004; Li et al. 2013; Lynn et al. 2011; Wang et al. 2007, 2018; Xu et al. 2010). Previous studies have focused on low latitudes especially for the equatorial region. In

\footnotetext{
*Correspondence: wn_22s_cetc@163.com

${ }^{1}$ School of Physics and Optoelectronic Engineering, Xidian University, Xi'an 710071, Shaanxi, China

Full list of author information is available at the end of the article
}

order to understand the global characteristics of spread-F, the variations at midlatitudes have attracted great interest of many researchers since 1980s. Bowman (1984) analyzed the data recorded at Brisbane $\left(36.4^{\circ} \mathrm{S}, 226.6^{\circ} \mathrm{E}\right)$ in Australia and showed a reduction in spread-F occurrence following an increased geomagnetic activity. Furthermore, data from two midlatitude ionosonde stations (Lannion in France and Canberra in Australia) of similar geomagnetic latitudes showed the latent correlations between spreadF occurrence and geomagnetic activity (Abdu et al. 1983; Bowman 1994; Hoang et al. 2010). Huang et al. (2011) compared the spread-F occurrence percentages using the data of two Chinese ionosonde stations located at Changchun $\left(43.84^{\circ} \mathrm{N}, 125.28^{\circ} \mathrm{E}\right)$ and Urumqi $\left(43.75^{\circ} \mathrm{N}, 87.64^{\circ} \mathrm{E}\right)$. The results showed that the spread-F occurrence at Changchun was higher than that at Urumqi especially during the 
low solar activity years and anti-correlations between the spread-F occurrence and the solar 10.7 fluxes. Bhaneja et al. (2018) investigated the seasonal and solar cycle variations in midlatitude spread-F at five different North American sites spanning between Puerto Rico $\left(18.5^{\circ} \mathrm{N}, 67.1^{\circ} \mathrm{W}\right)$ and California $\left(34.8^{\circ} \mathrm{N}, 120.5^{\circ} \mathrm{W}\right)$. They found that spread-F events occurred more frequently during solar minimum years for all five stations. The minimum spread-F occurrence percentages happened near spring equinox for all the sites except Vandenberg. Meanwhile, they found that the influence of geomagnetic on the spread-F occurrence was weak.

Most scholars did not classify spread-F when they discussed the statistical variations on the spread-F occurrence. In detailed studies, spread-F can be classified as the frequency spread-F (FSF) and range spread-F (RSF). The echo of FSF distributes spreading along the frequency axis close to the critical frequencies of the ordinary and extraordinary traces of the ionograms; hence, they are associated with irregularities nearby the $\mathrm{F}$ region peak; meanwhile, the echo of RSF distributes spreading along the vertical height axis. Some scholars have analyzed the differences between FSF and RSF occurrence. Chandra et al. (2003) analyzed the spread-F occurrences at Ahmadabad $\left(23^{\circ} \mathrm{N}, 72.4^{\circ} \mathrm{E}\right)$ in the Indian zone and Cachoeira Paulista $\left(22.5^{\circ} \mathrm{S}, 45^{\circ} \mathrm{W}\right)$ in Brazil. The RSF occurrences at Cachoeira Paulista always showed a maximum in summer during low-sunspot years, and similar phenomenon had been found at Ahmadabad. Hajkowicz (2007) studied the ionosonde data obtained over a wide range of southern latitudes (in latitude range: $23^{\circ} \mathrm{S}-52^{\circ} \mathrm{S}$ ). The spread-F at low midlatitude $\left(23^{\circ} \mathrm{S}-36^{\circ} \mathrm{S}\right)$ and midlatitude regions $\left(44^{\circ} \mathrm{S}-48^{\circ} \mathrm{S}\right)$ were characterized by a strong peak in RSF occurrence in winter, but an enhanced RSF activity was observed in local summer in Japan. Bhaneja et al. (2009) conducted a study using ionosonde data over a full solar cycle at Virginia $\left(37.95^{\circ} \mathrm{N}, 284.53^{\circ} \mathrm{E}\right)$. They found that the spread-F events occurred more frequently during the late fall or early winter particularly during solar minimum. RSF was more prevalent during solar minimum, whereas FSF was prevalent in solar maximum conditions. Chen et al. (2011) employed a digisonde at Wuhan $\left(30.5^{\circ} \mathrm{N}, 114.4^{\circ} \mathrm{E}\right)$, China, to observe the spread-F. They found that the FSF events were highly active in summer; meanwhile, the RSF showed very low occurrence during the whole night. Paul et al. (2018) investigated the occurrence rate of spread-F using the ionosonde data in the European longitude sectors (Nicosia, Athens and Pruhonice) during 2009, 2015 and 2016. He found that RSF in nighttime occurred more frequently in lower midlatitude regions during high solar activity, whereas FSF played the dominant role at higher midlatitudes.

The gravitational Rayleigh-Taylor instability $(\mathrm{R}-\mathrm{T})$ theory was the primary mechanism to explain the formation of irregularities in the equatorial region. Spread-F occurrences at midlatitudes are affected by many factors (Booker 1979; Bowman 1990; Fukao et al. 2004; Perkins 1973). One of them is the acoustic gravity wave (AGW). AGW was considered to be a seeding mechanism that creates density perturbations in the ionosphere, leading to spread-F at midlatitude regions. Since most of the AGWs in the ionosphere originate from the lower atmosphere, there should be some regional features of spread$\mathrm{F}$ occurrences due to the different local meteorological or ground conditions. Booker (1979) discussed the role of AGWs in the generation of spread-F and concluded that AGWs play a key role in the formation of spread-F. Bowman (1990) studied the data at Bribie Island $\left(27.05^{\circ} \mathrm{S}\right.$, $\left.153.16^{\circ} \mathrm{E}\right)$ and Moggill (60 $\mathrm{km}$ south of the Bribie Island) in Australia. They found that the F2 region combined with the observation of TIDs (traveling ionospheric disturbances) associated with the electron density depletions was fully consistent with the involvement AGWs. Many scholars found that the behavior of the AGWs in the midlatitude $\mathrm{F}$ region is related to the spread-F occurrence in the nighttime ionosphere (Bowman 1994, 1996, 1998; Bowman and Mortimer 2000, 2003; Chen et al. 2011; Dyson et al. 1995; Fukao et al. 2004). Xiao et al. (2009) presented an observational evidence for the AGWs' seeding of the ionospheric plasma instability by revealing the observational linkage between spread-F and AGWs based on the HF Doppler frequency shift measurements at Peking University. These observational facts showed the close relation between AGWs and spread-F and were regarded as the evidence of the seeding role of the AGWIs in the spread-F formation. Statistical results showed that the AGWs were not the only factor in triggering spread-F. Nighttime spread-F structures have been found following the Perkins-type instability processes (Perkins 1973). It is shown that such layers are linearly unstable at night, if the field-aligned integrated Hall conductivity exceeds the field line-integrated Pedersen conductivity. The instability involves the growth of an altitude perturbation, shaped like a plane wave, which is accompanied by large polarization electric fields. In addition, the spread-F has also been correlated with geomagnetic storms through the excitation of TIDs and subsequent $\mathrm{F}$ region uplifts. A series of complicated physical processes may lead to the generation of spread-F events. The Perkins instability theory is accepted as the most reasonable explanation of the spread-F phenomenon at midlatitudes.

The midlatitude region of Eastern Asia covers typical geomorphological features such as continents, oceans and land-sea junctions, the longitude span is large, and the longitude of geomagnetic field varies greatly. Therefore, a comparative statistical characteristic of the spread-F 


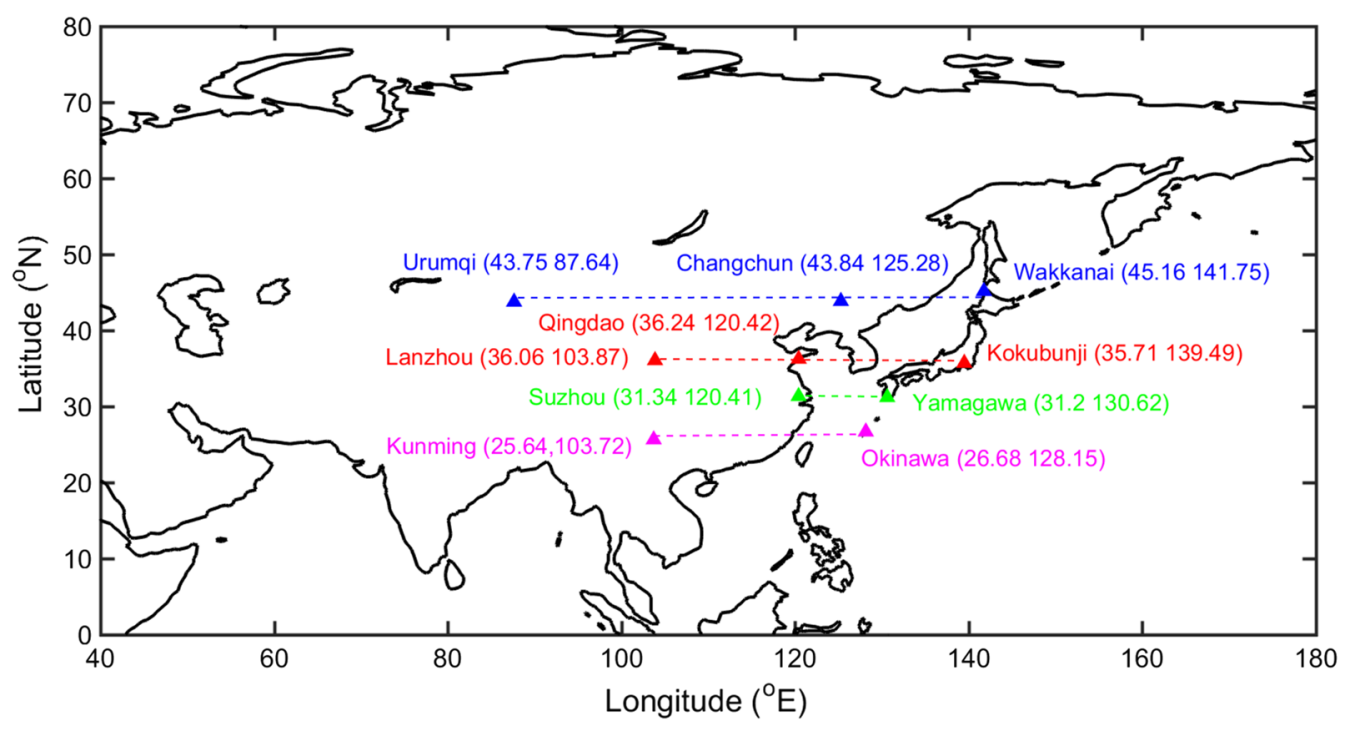

Fig. 1 Details of the digital ionosonde sites used in the investigation; these stations are located roughly at latitudes of 25, 31, 35 and 45

at different longitude regions in Eastern Asia is of great scientific significance. Due to insufficient data, few studies have been carried out on the longitudinal and latitudinal differences in spread-F occurrences at stations with similar geographical latitude in Eastern Asia. For a more detailed study, various types of spread-F occurrences should be examined separately. This paper aims to present the statistical comparison of FSF and RSF occurrence percentages using ionosonde data from six Chinese stations and four Japanese stations at midlatitudes. These stations are roughly distributed over four latitude chains. In particular, obvious differences among the 10 sites in terms of ground conditions, geographical environment and geomagnetic dip are observed where the sites are distributed within the mainland, on the coast and in island. The analysis focused on (1) the difference in FSF and RSF occurrence percentages at different sites located at nearly the same latitude, particularly on the variation in occurrence probability with solar and geomagnetic activities, season and local time; (2) the difference in FSF and RSF occurrence percentages between China and Japan from between $25^{\circ} \mathrm{N}$ and $45^{\circ} \mathrm{N}$ at midlatitudes; and (3) trying to find the possible mechanism for the difference in spreadF occurrence percentages. In "Data set and method of analysis" section, the source of the data and the method of analysis of spread-F occurrence are described briefly. "Statistical results and discussion" section presents the statistical results and discussion on the spread-F occurrences at the 10 stations. The probable mechanism of longitudinal and latitudinal differences was discussed in "Probable mechanism of longitudinal and latitudinal differences in spread-F occurrences" section. We summarize the conclusions in "Summary and conclusions" section.

\section{Data set and method of analysis}

China Research Institute of Radio-wave Propagation (CRIRP) built a long-term network of ionospheric observation stations covering the mainland of China. In this study, we extracted data of simultaneous spread-F that occurred during 1997 and 2016 from six digital ionosondes located at Kunming $\left(25.64^{\circ} \mathrm{N}, 103.72^{\circ} \mathrm{E}\right)$, Suzhou $\left(31.34^{\circ} \mathrm{N}, 120.41^{\circ} \mathrm{E}\right)$, Lanzhou $\left(36.06^{\circ} \mathrm{N}, 103.87^{\circ} \mathrm{E}\right)$, Qingdao $\left(36.24^{\circ} \mathrm{N}, 120.42^{\circ} \mathrm{E}\right)$, Urumqi $\left(43.75^{\circ} \mathrm{N}, 87.64^{\circ} \mathrm{E}\right)$ and Changchun $\left(43.84^{\circ} \mathrm{N}, 125.28^{\circ} \mathrm{E}\right)$. The download linkage of the ionosonde data from the four stations in Okinawa $\left(26.68^{\circ} \mathrm{N}, 128.15^{\circ} \mathrm{E}\right)$, Yamagawa $\left(31.2^{\circ} \mathrm{N}, 130.62^{\circ} \mathrm{N}\right)$, Kokubunji $\left(35.71^{\circ} \mathrm{N}, 139.49^{\circ} \mathrm{E}\right)$ and Wakkanai $\left(45.16^{\circ} \mathrm{N}\right.$, $\left.141.75^{\circ} \mathrm{E}\right)$ is provided in the Web site: http://wdc.nict. go.jp/. Details of the geographical coordinates and data set of the stations are presented in Fig. 1 and Table 1. The ionosonde data of Suzhou and Kunming used for this study were obtained in June 2009 and August 2007, respectively. For the convenience of comparison, the data used at Yamagawa and Okinawa stations in Japan were also obtained from 2009 to 2007.

The terrain or geographical location of the 10 stations is different. Urumqi is in the center of the EuropeAsia continent, whereas Changchun and Lanzhou are inland cities. Kunming is located in the middle-to-lowlatitude transitional area. This region is in the west of the Yunnan-Guizhou Plateau, near the special terrain of the Tibetan plateau where the ionosphere exhibits complex characteristics. Qingdao and Suzhou are situated in a typical coastal area in the midlatitude region. Wakkanai, Kokubunji, Yamagawa and Okinawa in Japan are all located in coastal areas. In this study, we used the spread-F occurrence percentages to describe the 
Table 1 Data set of 10 sites used in this study

\begin{tabular}{llll}
\hline Location & Symbol used & Data available & Data not available \\
\hline Kunming & KM & $2007-2016$ & $2007.1-2007.7$ \\
Okinawa & OKI & $2007-2016$ & \\
Suzhou & SZ & $2009-2016$ & $2009.1-2009.5$ \\
Yamagawa & YAM & $2009-2016$ & \\
Lanzhou & LZ & $1997-2016$ & \\
Qingdao & QD & $1997-2016$ & $1997.1-2000.8$ \\
Kokubunji & KOK & $1997-2016$ & \\
Urumqi & UR & $1997-2016$ & $1997.3-1997.12$ \\
Changchun & CC & $1997-2016$ & \\
Wakkanai & WAK & $1997-2016$ & $1997.9-1997.11,1998.1$, \\
& & & $3-4,12,1999.1,4-5$, \\
& & & $7-12,2000.3-4,5-12$ \\
\hline
\end{tabular}

spread-F statistical characteristic, which is defined as follows:

$$
p(y, m, h)=\frac{n(y, m, h)}{N(y, m, h)} \times 100 \%
$$

where $y, m$ and $h$ represent the year, month and local time (LT), respectively; $n$ is the number of FSF or RSF occurrences that appear at the same local time but on different days of a single month; and $N$ is the total number of observations in local time for a given year. To examine their seasonal variations, the data were grouped into the following four seasons: summer (May, June, July and August), spring equinox (March and April), autumn equinox (September and October) and winter (January, February, November and December). Since the spread-F is mostly a nighttime phenomenon, only data between local time 6:00 PM and 6:00 AM were considered in this study.

Meanwhile, solar and geomagnetic activities are the two main factors that influence the ionosphere activities. The data set covered the entire Solar Cycle 23 and more than half of Solar Cycle 24. Solar Cycle 24 was abnormal and different from the preceding solar cycles (Chen et al. 2011), and its maximum solar activity index was 50\% lower than the former one. We used F10.7 and Ap index to identify the solar and geomagnetic activities, separately. In order to obtain the relationship between the spread-F and the geomagnetic and solar activities, the spread-F events are divided into three or two groups based on the F10.7 or Ap index to conduct statistical studies, respectively (Abdu et al. 2003). The classification is listed as follows:

$\int$ F10.7 $\leq 100$ low solar activity levels

$\left\{\begin{array}{l}100<\text { F10.7 }<180 \text { medium solar activity levels } \\ \text { F10.7 } \geq 180 \text { high solar activity levels }\end{array}\right.$

and $\left\{\begin{array}{l}\text { Ap }<12 \text { quite day } \\ \mathrm{Ap} \geq 12 \text { disturbed day }\end{array}\right.$
In order to analyze the correlation between the spreadF occurrence rates and the F10.7 or Ap index, the normalized probability was used. The normalized spread-F occurrence rate is defined as follows:

$$
p_{i}=\frac{m_{i}}{\sum_{i} m_{i}} \sum_{i} p_{i}=1
$$

where $p$ is the normalized FSF or RSF occurrence rate and $\mathrm{m}_{\mathrm{i}}$ is the number of FSF or RSF event occurrences when F10.7 or Ap index is within a certain level.

\section{Statistical results and discussion}

Figure 2 shows the variation in daily F10.7, Ap index and monthly mean of FSF occurrence percentages with local time. Figure 3 shows how the daily F10.7, Ap index and total amount of FSF vary with local time. The following common features could be found: (1) the FSF occurrences frequently occurred after midnight; (2) when the solar 10.7 fluxes and Ap index increase, the FSF occurrences decrease at the 10 stations, meaning a negative correlation between the FSF occurrences and solar and geomagnetic activity; (3) FSF occurred mostly during the summer; (4) there is no significant difference in the total number of FSF between the 10 stations between 2004 and 2009. However, the total number of FSF in LZ, QD, KOK, SU, YAM, KM and OKI are obviously larger than that in the other three stations between 2010 and 2015. Most of the features are nearly in agreement with the results given by the other authors (such as Bowman 1996; Huang et al. 2011; Igarashi and Kato 1993; Niranjan et al. 2003). But there is some difference in this result. A large difference was found in the FSF occurrence percentages among the stations at nearly the same latitude. The FSF occurrence percentages at OKI were higher than those of KM. The maximum FSF occurrence percentage was approximately $80 \%$ and occurred in June 2010 and in July 2016 at OKI. However, the FSF occurrences at YAM were remarkably lower than those at SZ, especially between 2015 and 2016 when the FSF occurrences at YAM were less than 15\%. The FSF occurrences at LZ and QD were much larger than those at KOK, but the differences of FSF occurrences between UR, CC and WAK was not obvious. The peak occurrence percentages of FSF in these 10 stations can reach $88 \%$ approximately. Another noteworthy phenomenon is the higher FSF occurrence percentages in winter versus the increase in latitude. 


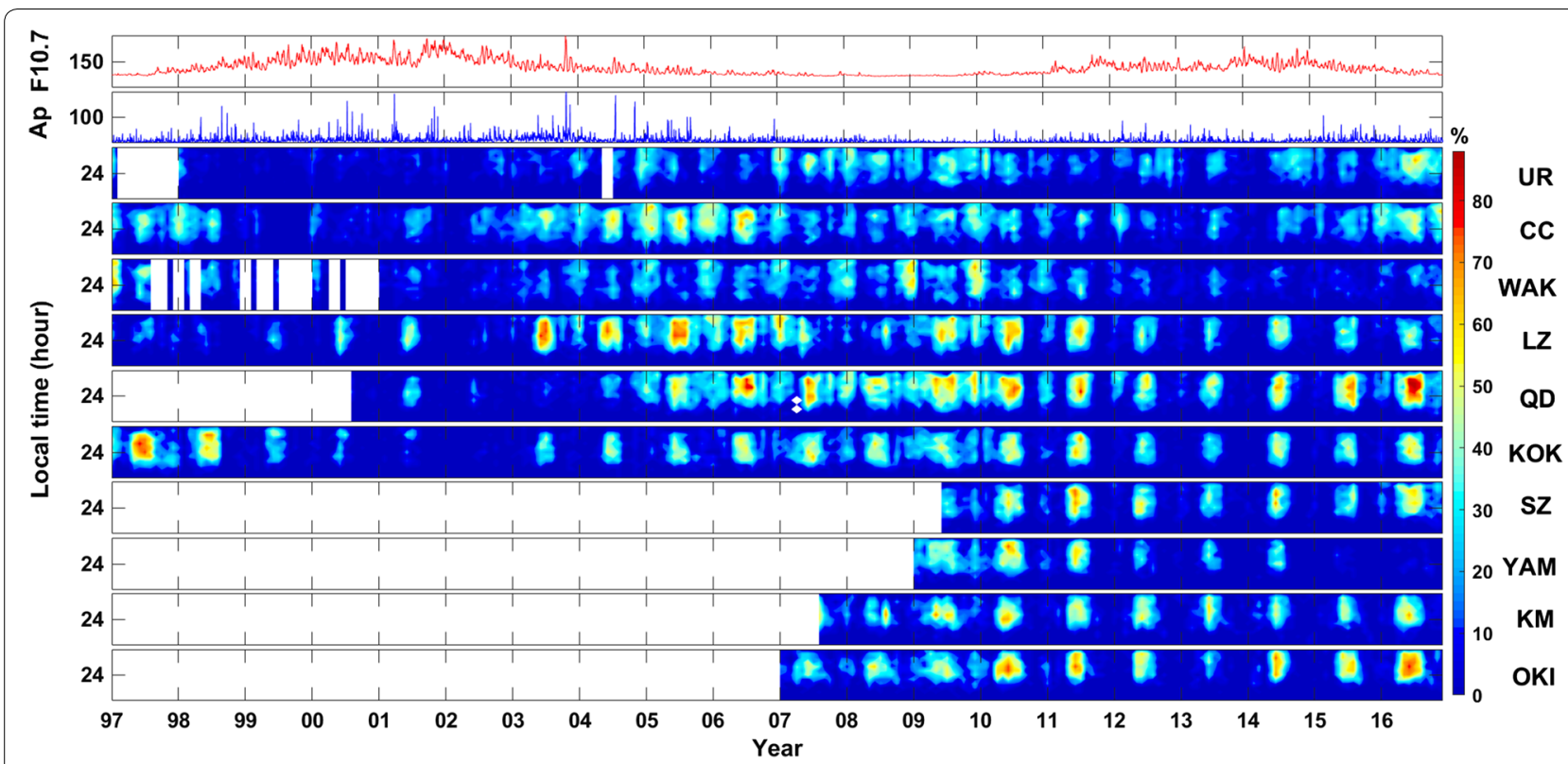

Fig. 2 Variations in daily F10.7, Ap index and monthly mean of FSF occurrence percentages at the 10 stations; the $x$-axis is the year and the $y$-axis is the local time

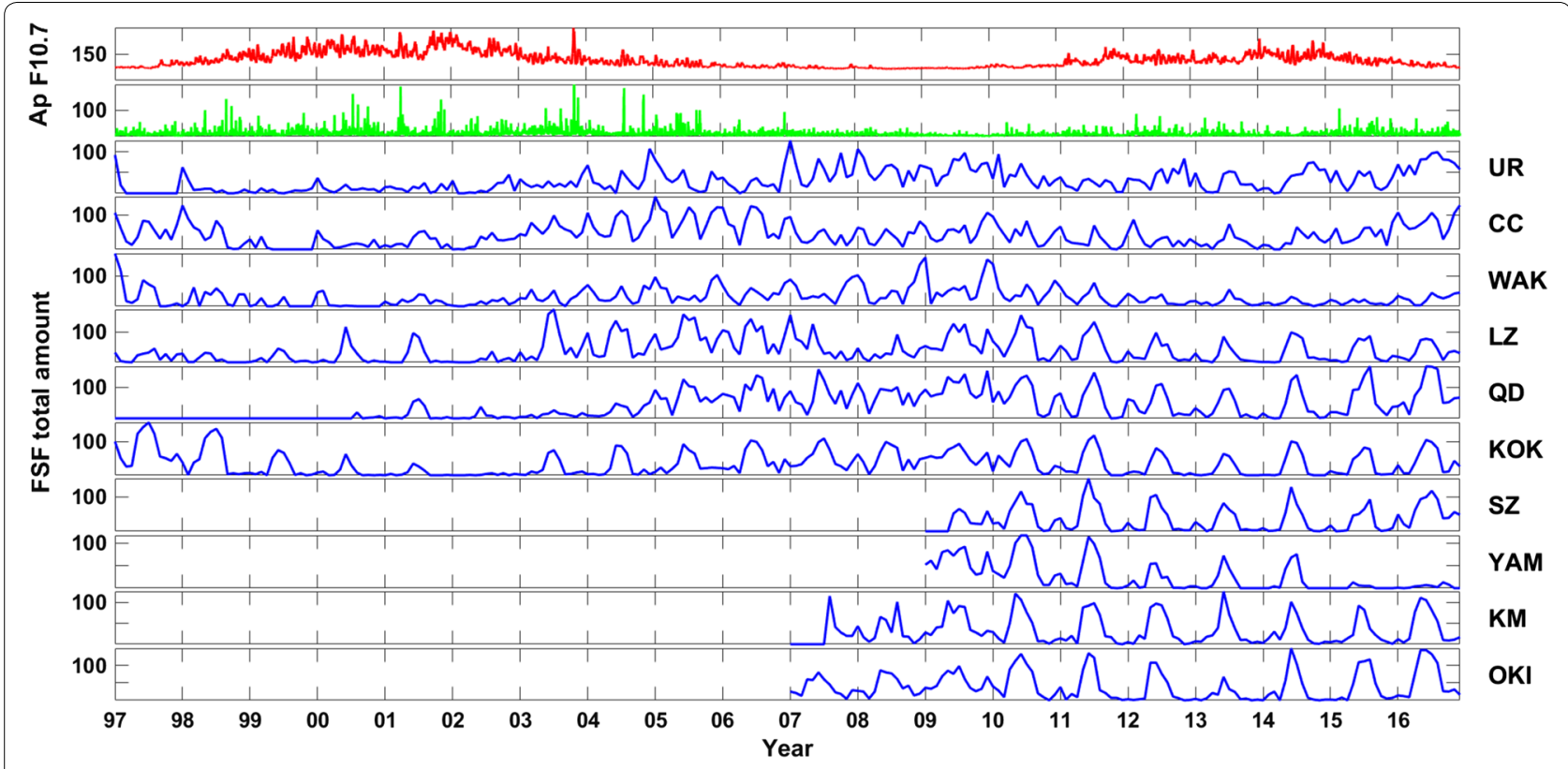

Fig. 3 Variations in daily F10.7, Ap index and FSF total amount at the 10 stations; the $x$-axis is the year and the $y$-axis is the FSF total amount

Therefore, the results at UR, CC and WK showed a more complex situation. Figures 4 and 5 reveal that normalized FSF occurrence percentages varied with local time on all the three solar activities and two geomagnetic activities levels. It can be seen that when F10.7 is less than to 100 , the normalized FSF occurrence percentages are the largest. In sunrise or sunset periods at SZ, KM, KOK and
OKI stations, the FSF occurrence percentages at medium solar activity level is sometimes even higher than those at low solar activity level. When the solar activity is high, there will be almost no FSF events at many stations. The normalized FSF occurrence percentages are much greater when Ap is less than 12. The results of Figs. 4 and 5 give 

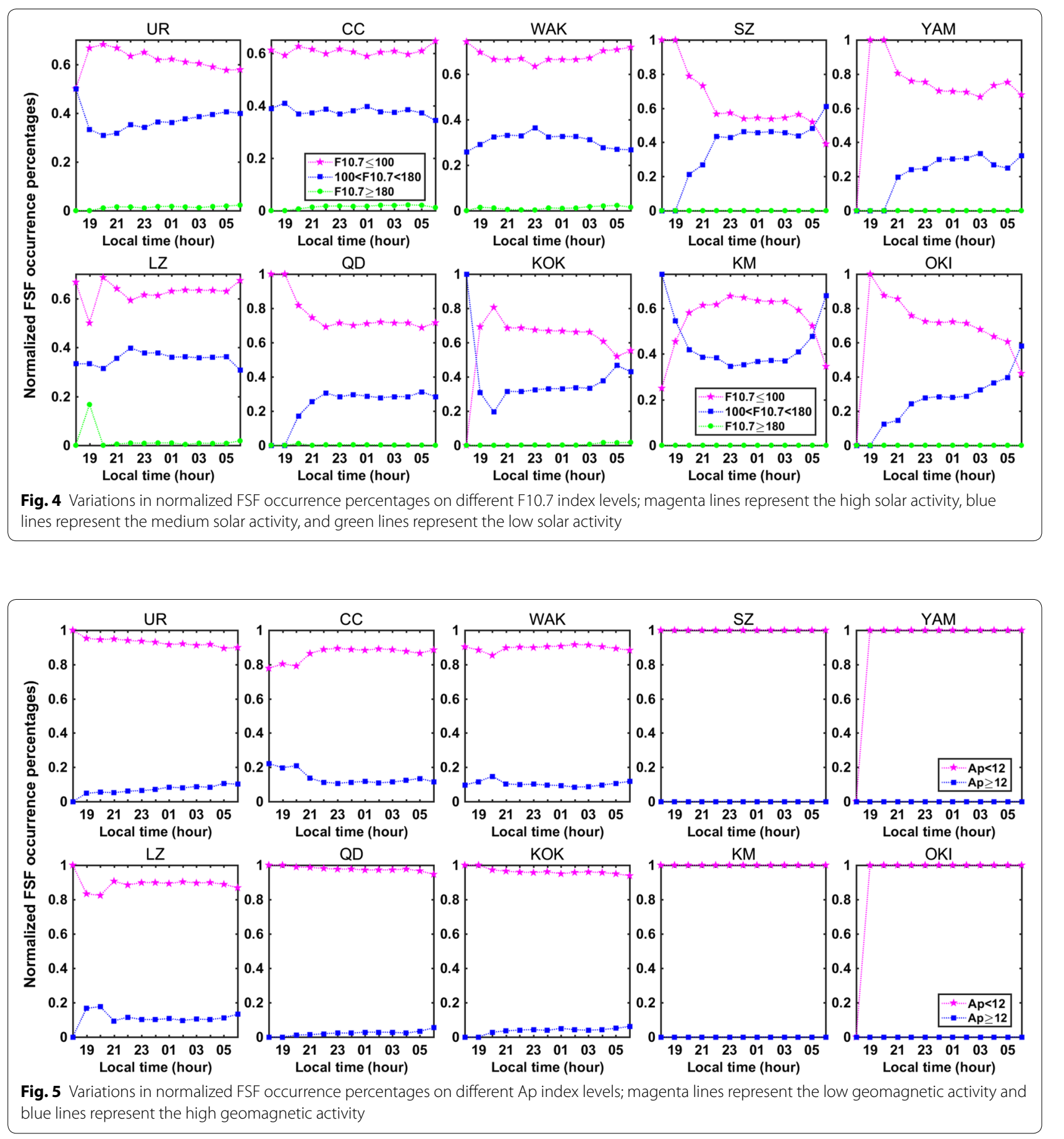

us a clearer understanding of the effect of solar or geomagnetic activity on the FSF occurrences.

Figures 6 and 7 show that the daily F10.7, Ap index and monthly mean of RSF occurrence percentages and FSF total amount vary with local time for the 10 stations. The variation on RSF occurrences was different from FSF in the following ways: (1) the RSF occurrences in these 10 stations are much lower than the FSF occurrences; (2) the RSF frequently occurs near midnight; (3) longitudinal changes in total amount of RSF in China and Japan. It seems that the RSF has a negative correlation with the solar or geomagnetic activity at LZ and QD. Meanwhile, no remarkable difference is observed in the RSF occurrences between SZ and YAM. Figures 8 and 9 show that 


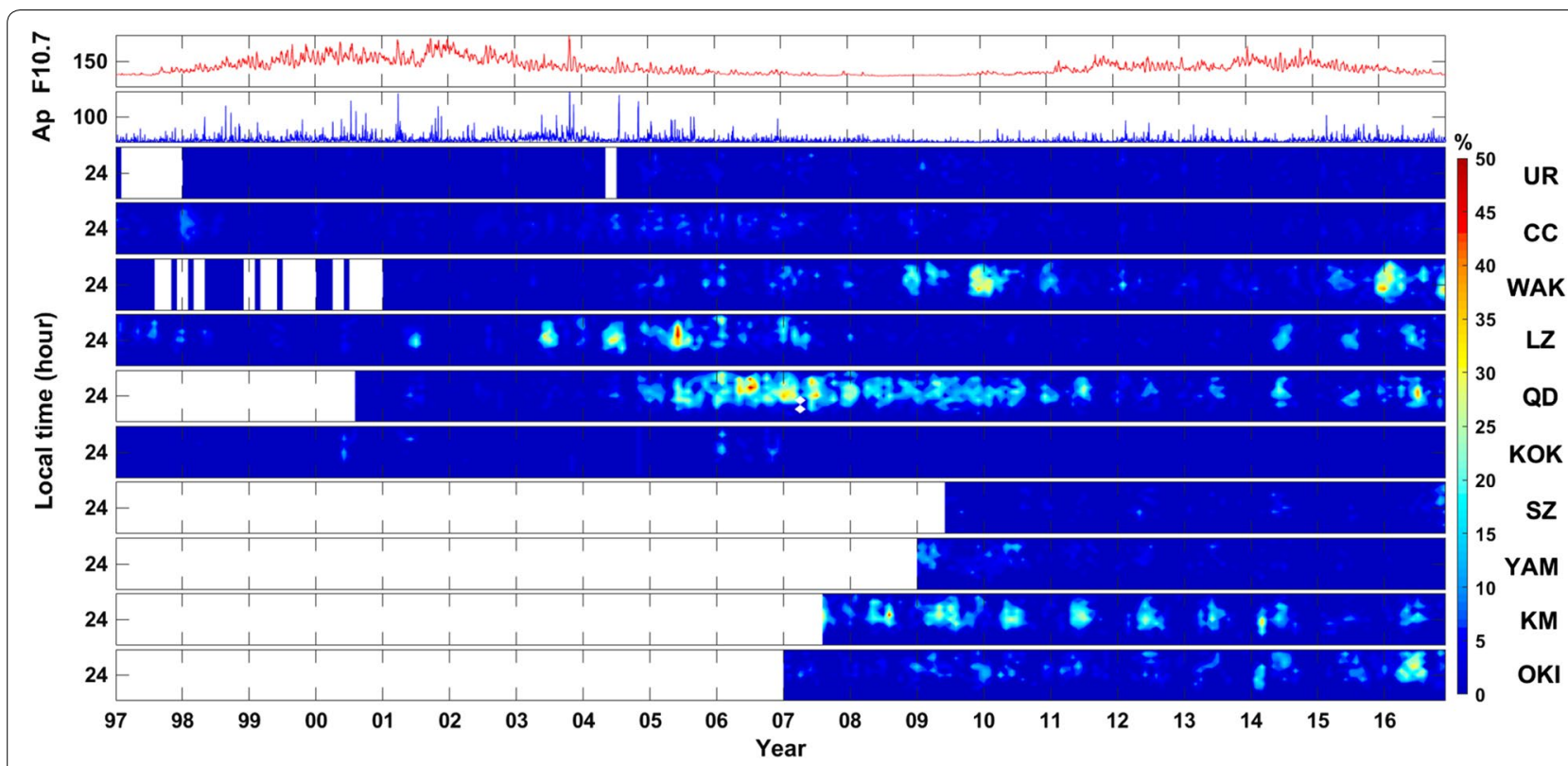

Fig. 6 Variations in daily F10.7, Ap index and monthly mean of RSF occurrence percentages at the 10 stations; the $x$-axis is the year and the $y$-axis is the local time

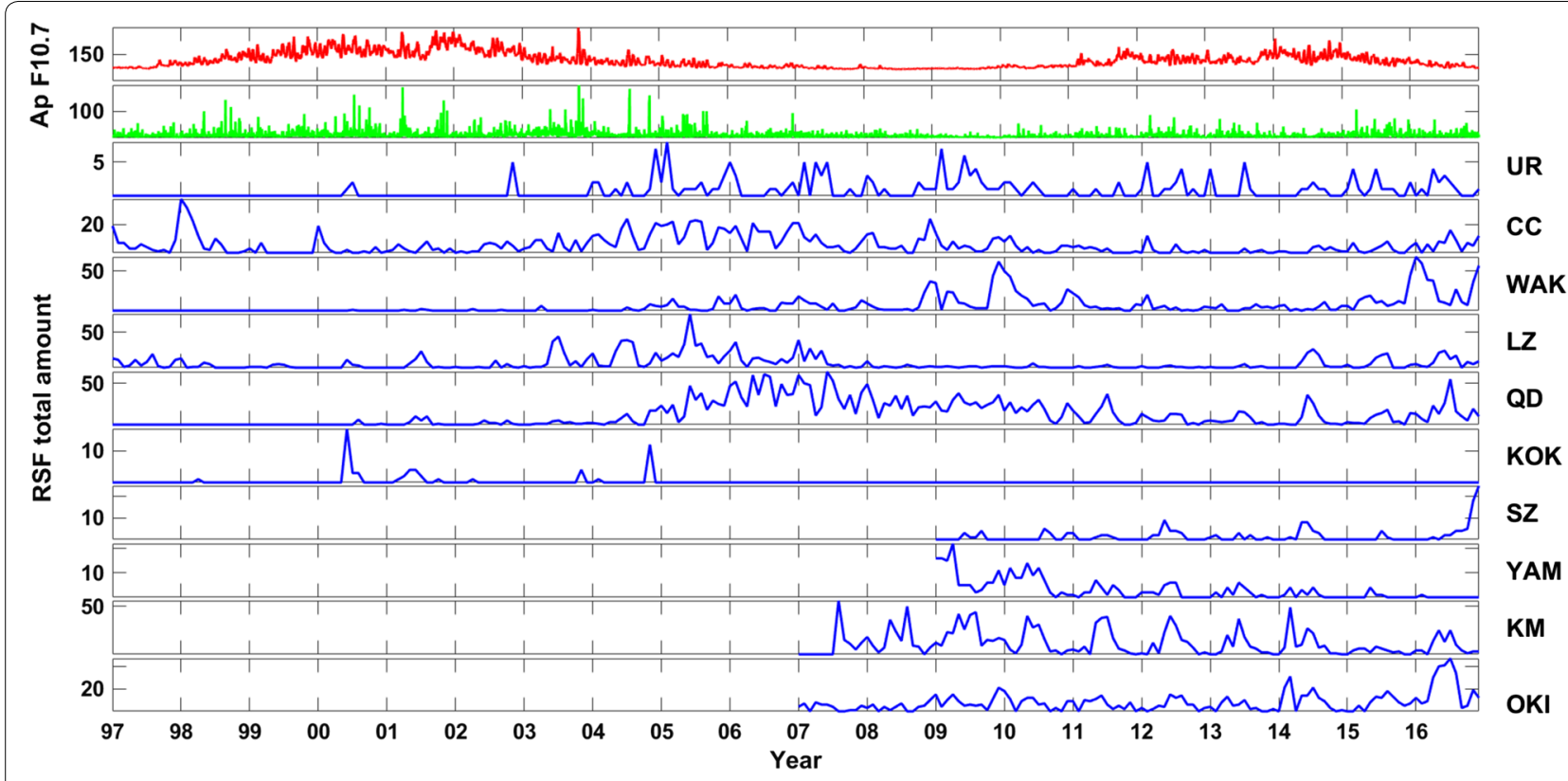

Fig. 7 Variations in daily F10.7, Ap index and RSF total amount at the 10 stations; the $x$-axis is the year and the $y$-axis is the RSF total amount

the normalized RSF occurrence percentages vary with local time on all the three solar activities and two geomagnetic activities levels. The normalized RSF occurrence percentages are the largest on the low solar activity except KOK. Moreover, the RSF occurrence percentages on medium solar activity are higher than those on low solar activity at some time of some stations.
The seasonal variations in the FSF occurrence percentages observed at the 10 sites are shown in Fig. 10. The FSF occurrences were higher during summer than during other seasons at LZ, QD, KOK, SZ, YAM, KM and OKI. Nevertheless, FSF occurred mostly during summer and winter at UR, CC and WAK. The FSF occurrence during winter is even higher than those 


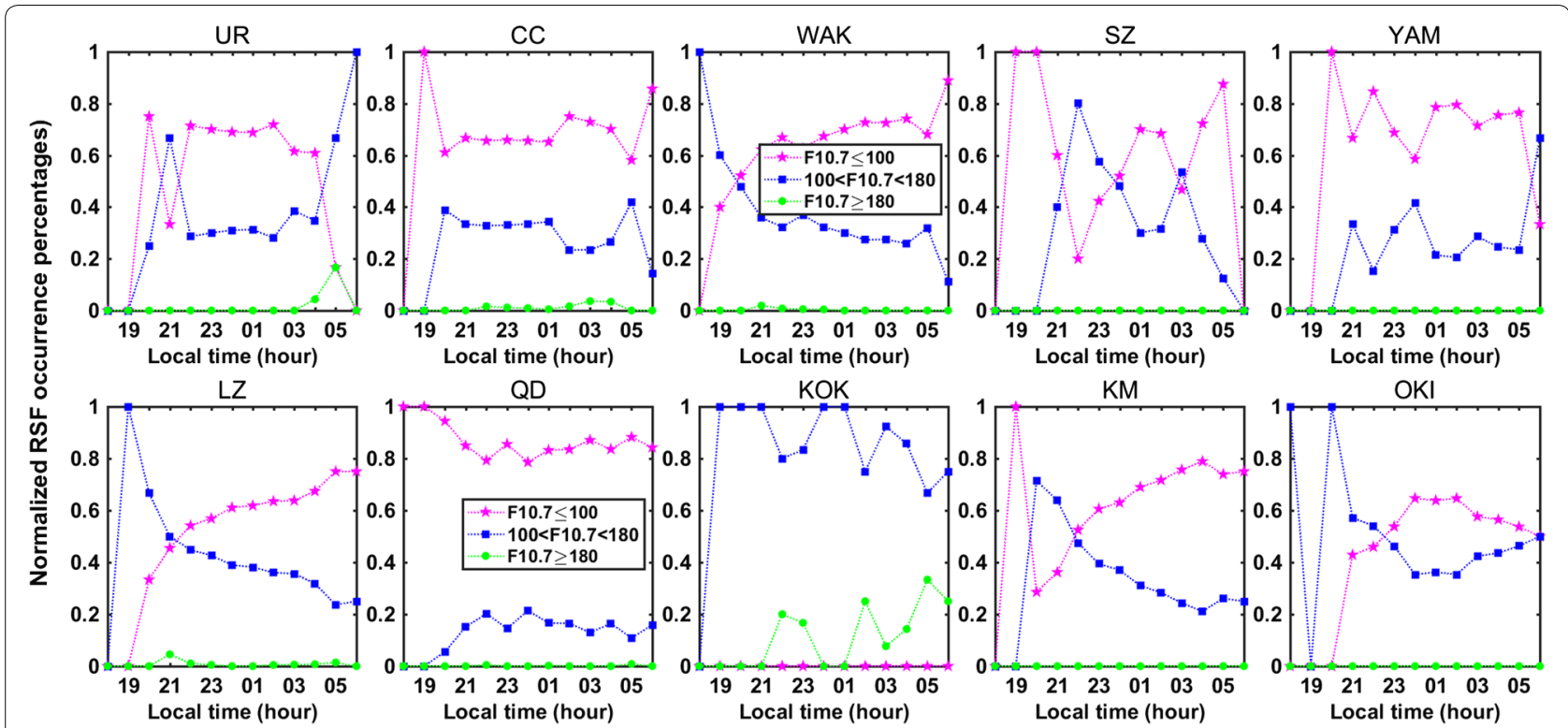

Fig. 8 Variations in normalized RSF occurrence percentages on different F10.7 index levels; magenta lines represent the high solar activity, blue lines represent the medium solar activity, and green lines represent the low solar activity

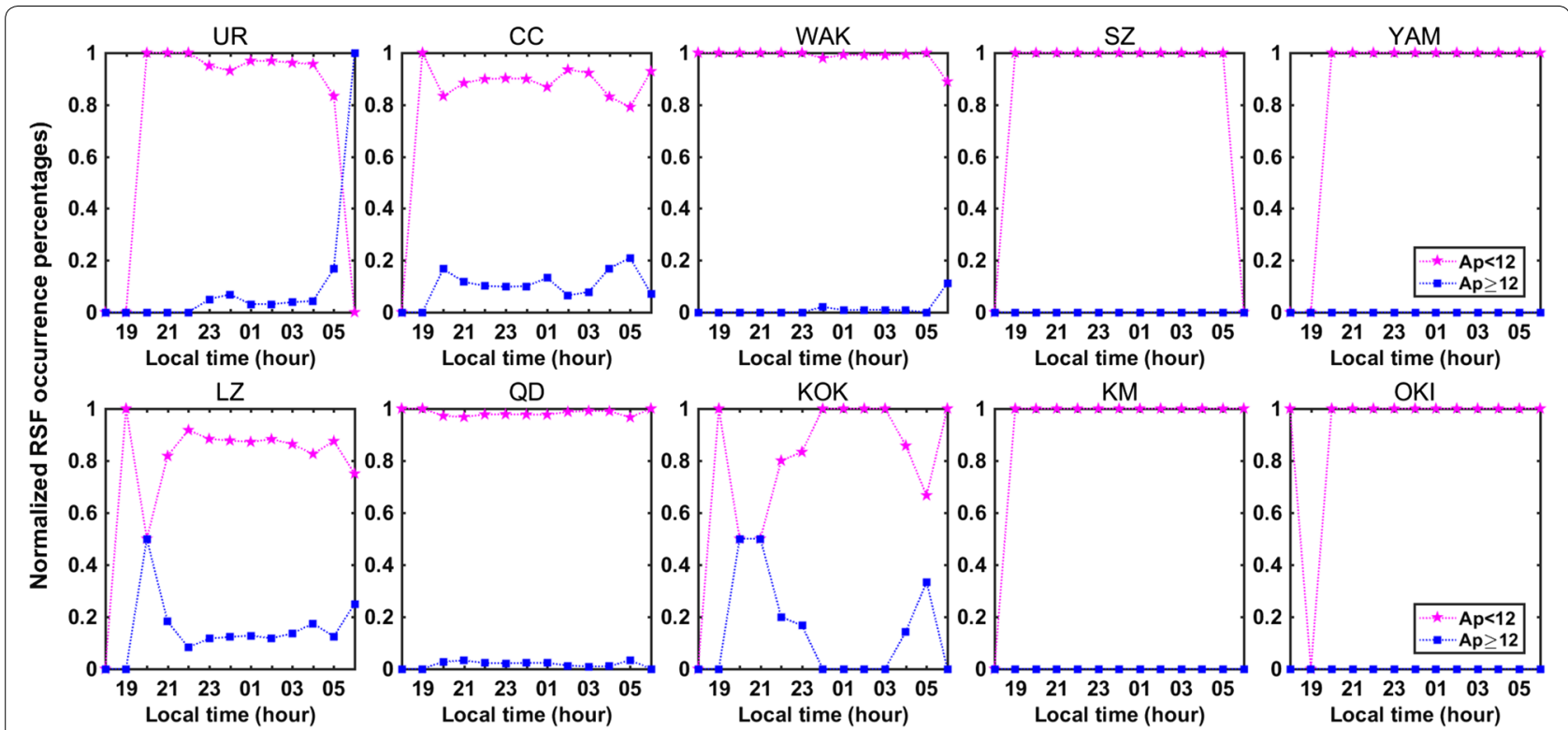

Fig. 9 Variations in normalized RSF occurrence percentages on different Ap index levels; magenta lines represent the low geomagnetic activity and blue lines represent the high geomagnetic activity

during summer at WAK. Another more obvious phenomenon is that the difference of FSF occurrence percentages in four seasons at LZ, QD, KOK, SZ, YAM, $\mathrm{KM}$ and OKI is greater than that at UR, CC and WAK. FSF occurrence percentages were higher during the autumn equinox than during the spring one at UR, $\mathrm{LZ}$ and QD. However, the difference between these two seasons is not obvious at the other sites. Figure 11 reveals the seasonal RSF occurrence percentage variations at the 10 sites. RSF occurred mostly in the winter months at UR, CC and WAK which is different from FSF. The RSF occurrences were higher during summer at SZ, LZ, QD, KOK, KM and OKI. However, the RSF occurred mostly during the vernal equinox at 

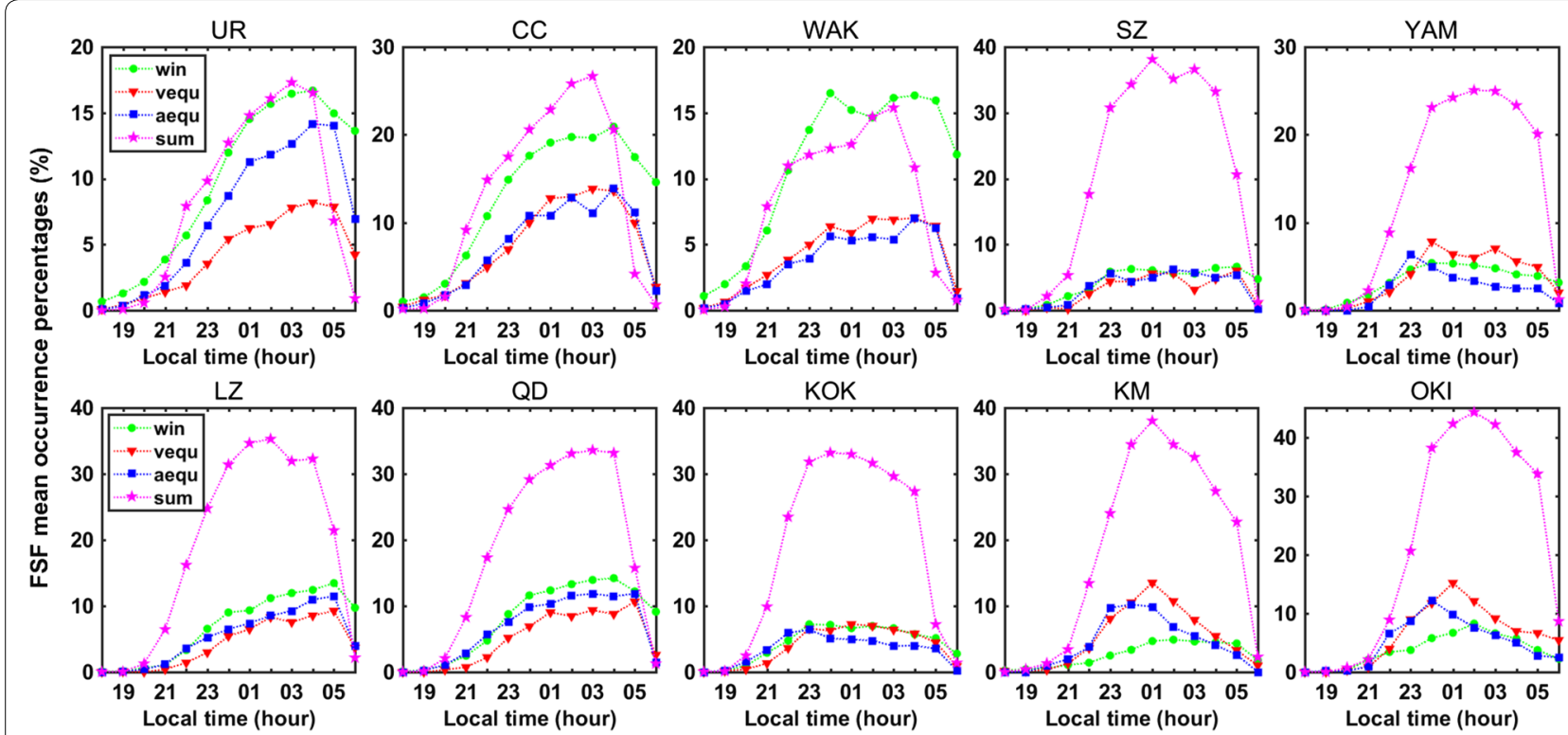

Fig. 10 Seasonal variations in FSF mean occurrence percentages; green, red, blue and magenta lines represent winter, vernal equinox, autumn equinox and summer, respectively
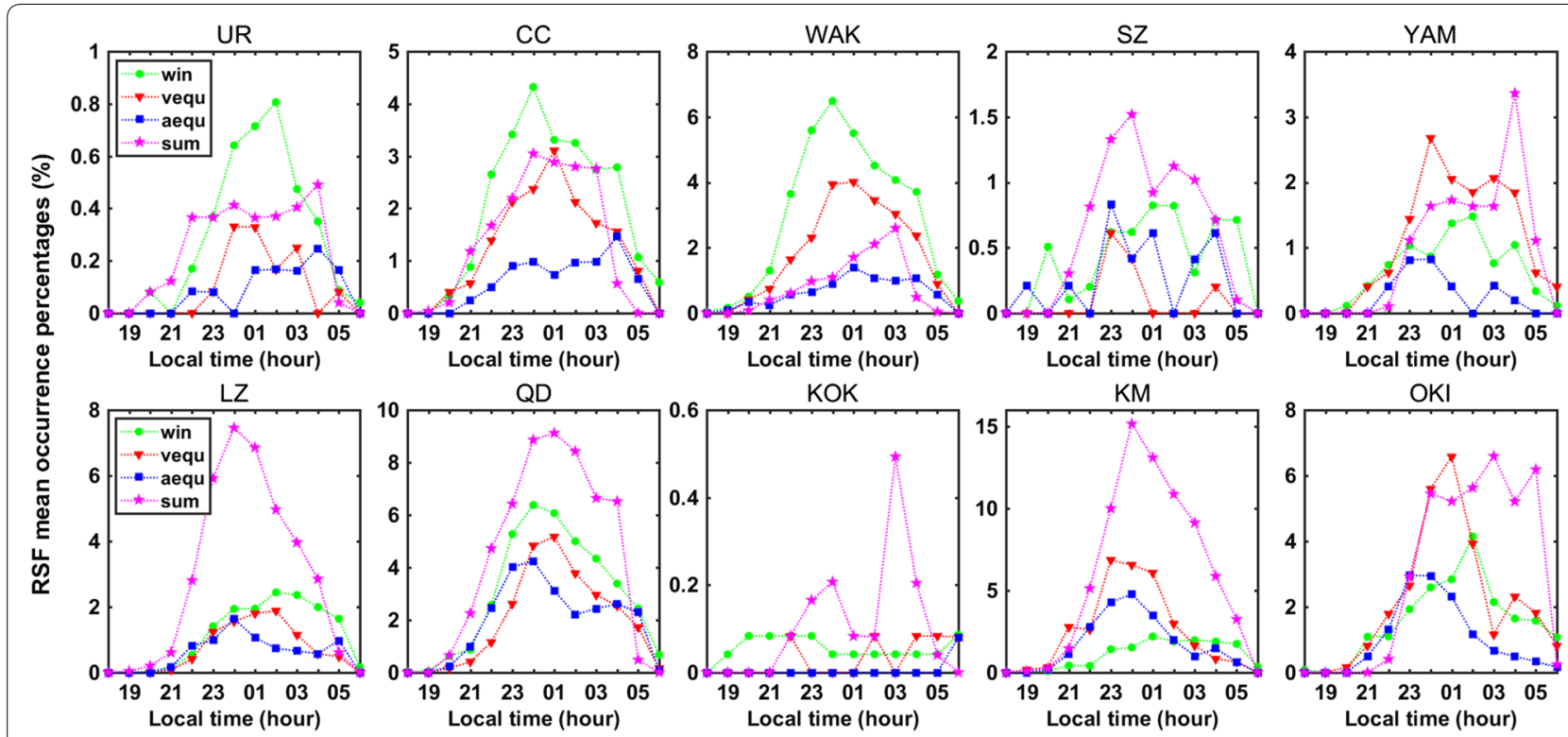

Fig. 11 Seasonal variations in RSF mean occurrence percentages; green, red, blue and magenta lines represent winter, vernal equinox, autumn equinox and summer, respectively

YAM. Figure 12 shows the local time variations in the monthly mean of FSF and RSF occurrence percentages. Statistically speaking, FSF started at 21:00 LT and lasted approximately until 05:00 LT. Meanwhile, the peak value of FSF occurrence percentages appeared at about 02:00 LT at CC, LZ, QD. At the four other sites in Japan, the peak occurrences were observed at 01:00
LT. As a contrast, the peak of RSF occurrence percentages appeared at approximately 00:00 LT except YAM. The FSF occurrence percentages decrease with the increase in longitude from $31^{\circ} \mathrm{N}$ to $45^{\circ} \mathrm{N}$ latitude. However, the RSF occurrence percentages increase with the increase in longitude near $45^{\circ} \mathrm{N}$ latitude. This difference still indicates a very strong longitudinal effect for the 


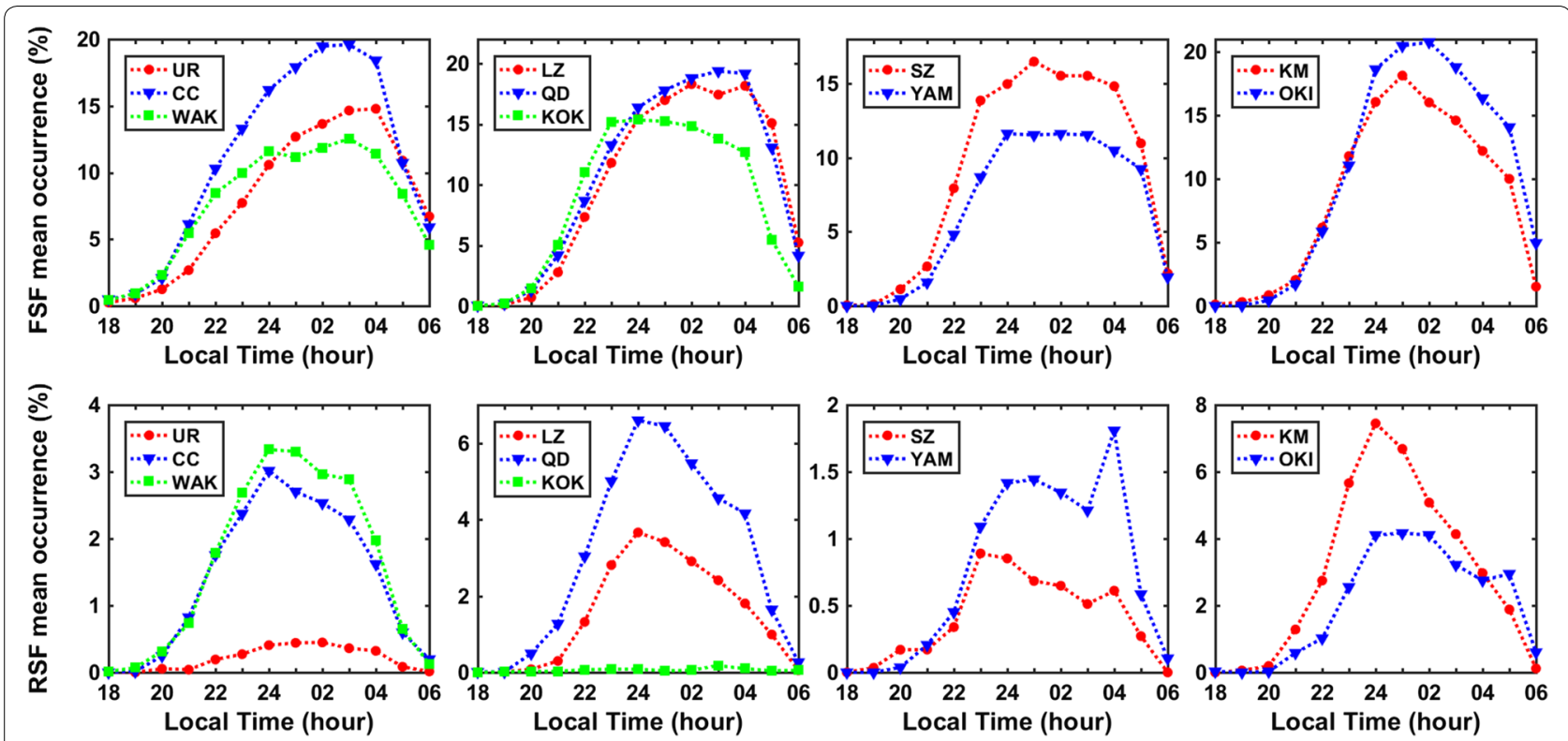

Fig. 12 Nocturnal variations in FSF and RSF mean occurrence percentages; the $x$-axis is the local time and the $y$-axis is the FSF or RSF mean occurrence

ten stations which located at almost the same latitudes. Some details will be discussed in the next section.

The main features of the spread-F occurrences from our statistics are in agreement with the midlatitude observations in the other sectors reported by other scholars (such as Bowman 1984, 1994, 1996; Deminov et al. 2005, 2009; Hanumath Sastri 1977; Ossakow 1981; Rao Rama et al. 2004). For example, the FSF occurrences have a negative correlation with the solar and geomagnetic activities, where the FSF occurrences reached maxima mostly during the summer months. The RSF occurred mostly during summer and winter at UR, CC and WAK, but only during summer at the other seven stations. The peak values of FSF occurrence appeared during the post-midnight period. This variation is the same as that pointed out by Igarashi and Kato (1993). By using the data of Far East stations, Igarashi and Kato (1993) have pointed out the same result where the spread-F occurrence peaks appeared from June to July in summer and from December to January in winter. Huang et al. (2011) investigated the spread-F occurrences at UR and CC stations; they found that (1) spread-F occurrence showed a high value during low solar activity and (2) spread-F occurred mostly in winter and summer. These features are the same as our findings as the data used at the same stations. A comprehensive statistical study of midlatitude spread-F in the North American sector was presented using the ionosonde data observed at Puerto Rico $\left(18.5^{\circ} \mathrm{N}, 67,1^{\circ} \mathrm{W}\right)$, Virginia $\left(37.95^{\circ} \mathrm{N}, 75.5^{\circ} \mathrm{W}\right)$, Texas $\left(32.4^{\circ} \mathrm{N}, 99.8^{\circ} \mathrm{W}\right)$, Colorado $\left(40^{\circ} \mathrm{N}, 105.3^{\circ} \mathrm{W}\right)$ and
California $\left(34.8^{\circ} \mathrm{N}, 120.5^{\circ} \mathrm{W}\right)$ (Bhaneja et al. 2018). Each station had a maximum spread-F occurrence during different seasons. The spread-F mostly occurred during winter in Texas. The annual maxima of spread-F occurrence over the lower midlatitude region $\left(<50^{\circ} \mathrm{N}\right)$ are found near summer solstices and independent of solar activity (Paul et al. 2018). And they also found that there was a clear inverse correlation between the spread-F occurrences with solar activity. These results are also consistent with our conclusions.

Abdu et al. (2003) showed that the RSF events are associated with developed or developing plasma bubble events, and the FSF events are associated with narrowspectrum irregularities that occur near the peak of the $\mathrm{F}$ layer. The difference in the mechanism possibly results in the difference in FSF and RSF occurrence percentages. Although differences were observed in the statistics for the RSF and FSF in each station, both types showed pronounced minima in occurrence percentages near solar maximum, and the RSF occurrences at these 10 stations in Eastern Asia were far lower than the FSF occurrences. Our conclusion agrees with the former results (Bhaneja et al. 2009; Hajkowicz 2007) where the maximum of the spread-F activity was present during the local summer in Japan. Our findings agree with the above statistical results, except the WAK station. Sinno and Kan (1980) and Huang et al. (1994) reported similar variations in the spread-F occurrences in Eastern Asia (Japan and Taiwan). Chen et al. (2011) found that the FSF and RSF have a minor occurrence peak in winter at Wuhan $\left(30.5^{\circ} \mathrm{N}\right.$, 
$\left.114.4^{\circ} \mathrm{E}\right)$. The variations on the spread-F occurrence in Wuhan are similar to that in Suzhou since both sites are located at similar latitude.

\section{Probable mechanism of longitudinal and latitudinal differences in spread-F occurrences} The longitudinal and latitudinal effects of the spread-F occurrences at midlatitude have been discussed by many authors (Huang et al. 2011; Kherani et al. 2009; Wang et al. 2018; Perkins 1973; Yakoyama et al. 2008; Zhou et al. 2005). They argued that AGW and Perkins instability may be the main mechanism for the occurrence and evolution of spread-F at midlatitude. In this case study, 10 stations at exactly four longitudes from approximately $25^{\circ} \mathrm{N}-45^{\circ} \mathrm{N}$ were selected to further investigate the FSF and RSF occurrences. These 10 stations are obviously different in geographical environment. Some stations are located in typical inland cities, other sites are in coastal areas and the rest are surrounded by oceans. The most striking fact is that both FSF and RSF occurrences at ocean or ocean-land junction regions are higher than those at inland regions at $35^{\circ} \mathrm{N}$ and $45^{\circ} \mathrm{N}$ latitude.

\section{The possible impact of AGW on the spread-F occurrence percentages}

Earlier studies showed that the midlatitude spread-F occurrence was influenced by several factors such as electron density gradient, neutral wind, electric field, local geomagnetic field and AGW. Although the role of AGW in the spread-F evolution is still not proved yet, many discussions have been conducted on the role of the AGW in triggering spread-F both theoretically and observationally (Booker 1979; Bowman 1990, 1994, 1996, 1998, 2001; Kherani et al. 2009; Huang and Kelly 1997; Xiao et al. 2009). Direct measurements of the AGWs near the ground surface are difficult, considering that their amplitude is extremely small in lower atmosphere. However, AGWs are still considered one of the important driving mechanisms for midlatitude spread-F. It is well known that most of AGWs in the ionosphere originate from lower atmosphere and ground conditions are one of the determining factors in generating AGWs. Huang et al. (2011) found that the AGW play an important role among the factors of the spread-F occurrences due to the different ground conditions by using the ionosonde data of UR and CC in China. The two stations have remarkable discrepancies of ground meteorological conditions. CC station is located near the coast, whereas UR is located in the very center of the Europe-Asia continent. The results showed that the spread-F occurrences at $\mathrm{CC}$ was always much higher than those at UR. This result has aroused our great interest. In this study, QD and CC lies near the coast, whereas LZ and UR is located in the Europe-Asia continent. The FSF and RSF occurrences at QD and CC were higher than those at $\mathrm{LZ}$ and UR. This seems that the spread-F occurrence near the sea is greater than that in inland stations. But the spread-F occurrences at many other sites are not so. The RSF occurrences at WAK and YAM are greater than those at other sites at near the same latitude. Meanwhile, the FSF occurrence at OKI is greater than that at KM. This result indicates that the generation of spread-F is not only influenced by AGW, but also by other factors. It is certain that different locations provide different source conditions for AGW generation, which in turn present different influences on the spread-F occurrence. For the ten stations, although some of them have near the same geographical latitude, there is large disparity in their terrain topography. This is important because they give different source conditions of AGW's generation which gives different influences on the spread-F occurrence. Our result also verifies the correctness of the conclusion obtained by Huang et al. (2011). On the other hand, Huang et al. (2011) pointed that the spread-F occurrences at CC and UR tended to be higher in summer and winter seasons than in equinox. Our findings also confirm this conclusion.

Kherani et al. (2009) examined the influences of AGWs on the evolutions of plasma bubbles deduced from the observations in Brazil. These findings clearly indicated the impact of AGWs seeding on the growth of plasma bubbles, thereby influencing the spread-F occurrence. Abdu et al. (2009) also discussed the role of AGW in the equatorial region and pointed out that the polarization electric field in an instability development can enhance under the action of AGWs. Observationally, the role of AGW as a seeding has been discussed by many authors (Nicolls and Kelley 2005; Xiao and Zhang 2001; Xiao et al. 2009; Pietralla et al. 2017; Kherani et al. 2009). Xiao et al. (2009) revealed a close relation between the AGWs and the midlatitude spread-F by analyzing 6-year $\mathrm{HF}$ Doppler records. Now our work provides observational facts on the large difference of spread-F occurrence percentages at ten stations that are approximately at similar geographical latitudes. However, for the stations in each group, there is a large disparity in their terrain topography. Considering the seeding role of AGW in excitation of the spread-F events, it could be reasonably assumed that levels of AGW activities are different in the $\mathrm{F}$ regions over the ten stations. This may be very important because they give different source conditions of AGW's generation which may lead to variations in differences in spread-F occurrences.

Wang et al. (2018) used the ionosonde data of Haikou, Guangzhou, Beijing and Changchun to investigate spread-F occurrence percentages, the possible threshold of foF 2 for FSF occurrence and the relationship between $\mathrm{h} F$ and RSF 
occurrence. They pointed out that the difference in foF2 and $h$ $F$ at different longitudes brought the variation in the spread-F occurrences. Additionally, we also checked the foF2 and $h$ F data at the 10 sites in this paper, but the results showed that there were no obvious differences of foF 2 and $\mathrm{h} F$ between the stations at nearly the same latitudes. Furthermore, it is well known that the variation in foF2 is connected with the heights of F2 region, so it may also affect spread-F occurrence percentages, but not the key factor in determining the difference of spread-F occurrences here. Meanwhile, even under favorable background conditions, certain triggering factors like AGW, electric field and so on are often needed for the spread-F occurrences. Therefore, our results indicated that the AGW was an important factor for spread-F event, but not the only one.

\section{The possible impact of Perkins instability on the spread-F occurrence percentages}

In contrast to the rich observational history for low-latitude spread-F, observations of spread-F at midlatitudes are relatively poor. Despite this brief history, a consistent understanding of climatological behavior of the spread-F in longitudinal occurrence has emerged from a variety of observational techniques. Perkins (1973) had proposed a system including three coupled nonlinear partial differential equations that could provide a basis for an instability process consistent with the spread-F event in the midlatitude ionosphere when appropriately solved. Hence, Perkins instability is now accepted as the most reasonable explanation of the spread-F phenomenon at midlatitudes (Kelley and Fukao 1991; Miller 1997; Zhou et al. 2005). The nighttime ionosphere at midlatitudes is typically dynamically stable as the upward $E \times B$ drift due to eastward electric field and/or equatorward neutral wind supports the $F$ region plasma against downward, gravity-driven diffusion (Perkins 1973). This equilibrium can be written by using an effective electric field $E_{0}^{*}=E+U \times B$, where $\mathrm{E}$ is electric field, $\mathrm{U}$ is neutral wind and $B$ is magnetic field (Kelley et al. 2003):

$$
\frac{\left|E_{0}^{*}\right| \cos \theta}{B} \cos D=\frac{g}{\left\langle v_{i n}\right\rangle} \sin ^{2} D
$$

where $\theta$ is an angle between $E_{0}^{*}$ and geomagnetic east, $D$ is the dip angle of the magnetic field, $g$ is the magnitude of the gravitational acceleration at the F layer height and $v_{i n}$ is the density-weighted collision frequency. The left and right sides are balanced in the steady state. The simple form of the linear growth rate for the Perkins instability is given as (Perkins 1973):

$$
\begin{aligned}
\gamma & =\frac{E_{0}^{*} \cos D}{B H} \sin (\theta-\alpha) \sin \alpha \\
& =\frac{g \sin ^{2} D}{\langle\nu\rangle_{0} H} \frac{\sin (\theta-\alpha) \sin \alpha}{\cos \theta}
\end{aligned}
$$

where $\alpha$ is the angle between geomagnetic east and the wave vector, $\langle v\rangle_{0}$ is the background of $\left\langle v_{i n}\right\rangle, H$ is the neutral scale height and $\gamma$ is proportional to the effective electric fields and $\sin (\theta-\alpha) \sin \alpha$. Since $U$ blows southeastward during the nighttime in the northern hemisphere due to a diurnal time, $E_{0}^{*}$ would typically be northeastward. The dip angle of the magnetic field over the 10 sites in this study is very different. The dip angle of the magnetic field decreases with the increase in longitude at the same latitude whenever under high or low solar activity. Therefore, the dip angle of the magnetic field at UR is the largest, and the dip angle of the magnetic field at OKI is the smallest. The largest dip angle is about $64^{\circ}$, and the smallest one is about $38^{\circ}$. This will probably cause the differences between $E_{0}^{*}$ and $\sin (\theta-\alpha) \sin \alpha$ at different sites and then cause the difference in growth rate of Perkins instability which may lead to the variation in spread-F occurrence percentages.

Considerable effort is currently being made to increase the understanding of the spread-F occurred at midlatitude and the suggested Perkins instability process. Yakoyama et al. (2008) developed a three-dimensional numerical simulation in the nighttime midlatitude ionosphere and applied to the Perkins instability evolution in the F region. Nevertheless, they found that the growth rate of Perkins instability is too small to explain some observational results. So it is necessary to consider other mechanisms to intensify the instability in the $\mathrm{F}$ region. Furthermore, although the southeastward neutral wind in the post-sunset period is suitable for generating the irregularity structure through the Perkins instability, the dynamo electric field induced by neutral wind is southwestward. The electric field can also modulate the F region and seed the Perkins instability. Therefore, the actual physical process is more complicated. In spite of this, the Perkins instability can still be invoked to partly explain the statistical results in this manuscript. The AGW or Perkins instability may be one of the causes of the spread-F events. To determine whether the spread-F variation is due to the lower atmosphere and ground condition influences, further studies using weather observation data (including the weather satellite images or other meteorological data) should be conducted. Therefore, further investigation about the mechanisms for the spread-F occurrences is still needed.

\section{Summary and conclusions}

In this study, we investigated the variations in the FSF and RSF occurrences, and the possible mechanisms for the longitudinal differences in the spread-F occurrence percentages at midlatitudes in Eastern Asia include the years of the data used in 23rd and 24th solar cycles. The major conclusions are summarized as follows: 
(1) The occurrence percentages of FSF in these ten stations are higher than RSF. The FSF occurrence percentages are higher during the low solar activity years at all sites. Moreover, the spread-F occurrences are anti-correlated with the geomagnetic activity. The spread-F events seldom occur at some sites when F10.7 $\geq 180$ or Ap $\geq 12$.

(2) The FSF occurred mainly during the summer except WAK, whereas the RSF occurred mostly in the winter at UR, CC and WAK. Post-midnight FSF was the most frequently observed type of spread-F events, whereas the peak value of the RSF occurrence appeared at approximately 00:00 LT.

(3) Spread-F occurred more often at coastal or marine areas than at inland area especially near $35^{\circ} \mathrm{N}-45^{\circ} \mathrm{N}$ latitudes due to different geographical locations. Nevertheless, the mean occurrence of FSF at SZ is higher than that at YAM. The mean occurrence of RSF at KM is higher than that at OKI. Another phenomenon that needs more attention is that FSF and RSF mean occurrences at $31^{\circ} \mathrm{N}$ latitude are the lowest for the four latitude chains.

(4) It is well known that the AGW and Perkins instability both likely play important roles in the spread-F occurrences. Due to the limitation of data, the generation mechanism of spread-F should be further studied.

This study presented a preliminary variation in the spread-F occurrence percentages including some new results, which is helpful in understanding the ionospheric variation in Eastern Asia. The above data and statistical results presented in this paper can be used as a reference for future studies.

\section{Abbreviations \\ FSF: frequency spread-F; RSF: range spread-F; EIA: equatorial ionization anomaly; F10.7: the monthly average data of solar $10.7-\mathrm{cm}$ radio flux; R-T: Rayleigh-Taylor; PRE: pre-reversal electric field; TID: traveling ionospheric disturbance; AGW: acoustic gravity wave; CRIRP: China Research Institute of Radio-wave Propagation.}

\section{Authors' contributions}

WN designed the study, analyzed the data and wrote the manuscript. GLX, XZW and ZZW contributed related analysis on data in China. XT and HYL contributed related analysis on data in Japan. DZH and ZZW helped with the text of the paper, particularly with the introduction and comparison with previous works. All coauthors contributed to the revision of the draft manuscript and improvement of the discussion. All authors read and approved the final manuscript.

\section{Authors' information}

Ning Wang is currently a Ph.D. student at Xidian University. She also is an Associate Professor at the China Research Institute of Radio-wave Propagation. She has authored and coauthored eight patents and over 16 journal articles. Her research interests are in ionospheric irregularities and ionospheric radio-wave propagation. Dr. Linxin Guo is currently a Professor and Head of the School of Physics and Optoelectronic Engineering Science at Xidian University, China.
He has been a Distinguished Professor of the Changjiang Scholars Program since 2014. He has authored and coauthored four books and over 300 journal articles. Dr. Zonghua Ding is currently an Associate Professor at the China Research Institute of Radio-wave Propagation. His research interests are ionospheric sounding and ionospheric radio-wave propagation. Dr. Zhenwei Zhao is currently a Professor and Chief engineer at the China Research Institute of Radio-wave Propagation. His current positions include: Chairman of the ITU-R SG3 in China; Head of the Chinese Delegation of ITU-R SG3 and Lead expert for the Asia-Pacific Space Cooperation Organization (APSCO). Dr. Zhengwen $\mathrm{Xu}$ is currently a Professor and also the Vice Director in the National Key Laboratory of Electromagnetic Environment, CRIRP. His research interests mainly include ionospheric physics and radio propagation, electromagnetic waves in random media, ionospheric remote sensing and ionospheric effects on radio systems. Dr. Tong Xu is currently an Associate Professor at the China Research Institute of Radio-wave Propagation. His research interests include ionospheric physics, ionospheric modeling, ionospheric forecast and radio propagation. Yanli Hu is currently an engineer at the China Research Institute of Radio-wave Propagation. Her research interests are mainly focused on ionosphere physics and ionospheric radio propagation.

\section{Author details}

${ }^{1}$ School of Physics and Optoelectronic Engineering, Xidian University, Xi'an 710071, Shaanxi, China. ${ }^{2}$ State Key Laboratory of Space Weather, Chinese Academy of Sciences, Beijing 100190, China. ${ }^{3}$ National Key Laboratory of Electromagnetic Environment, China Research Institute of Radio-wave Propagation, Qingdao 266107, Shandong, China.

\section{Acknowledgements}

The authors would like to thank the NICT of Japan for the ionosonde data sharing (four ionosonde stations: Okinawa, Yamagawa, Kokubunji and Wakkanai). The authors would like to thank the NOAA for the F10.7 and Ap data service. The authors would like to thank Dr. Shuji Sun for proofreading this manuscript. The authors would like to thank the anonymous referee for the useful comments and suggestions for improving the paper.

\section{Competing interests}

The authors declare that they have no competing interests.

\section{Availability of data and materials}

The ionosonde data in China are in the Web site: ftp://ftp-out.ips.gov.au/. The ionosonde data in Japan are in the Web site: http://wdc.nict.go.jp/IONO/. The authors would like to thank the NICT of Japan for the ionosonde data sharing. Regretfully, the data in China used in this manuscript cannot be shared because they belonged to the China Research Institute of Radio-wave Propagation (CRIRP).

\section{Consent for publication}

Written informed consent was obtained from study participants for participation in the study and for the publication of this report and any accompanying images. Consent and approval for publication was also obtained from Xidian University and China Research Institute of Radio-wave Propagation.

\section{Funding}

This work was supported by the National Natural Science Foundation of China (Grant No. 41604129), the National Key Laboratory Foundation of Electromagnetic Environment (Grant No. A171601003) and the Specialized Research Fund for State Key Laboratories. The funds from Grant No. 41604129 and the Specialized Research Fund for State Key Laboratories were used for data collection and analysis. The fund from Grant No. A171601003 was used for manuscript preparation.

\section{Publisher's Note}

Springer Nature remains neutral with regard to jurisdictional claims in published maps and institutional affiliations.

Received: 23 August 2018 Accepted: 13 April 2019

Published online: 23 April 2019 


\section{References}

Aarons J, Mullen JP, Whitney HE, Mackenzie EM (1980) The dynamics of equatorial irregularity patch formation, motion, and decay. J Geophys Res Space Phys 85(A1):139-149. https://doi.org/10.1029/JA085iA01p00139

Abdu MA, Bittencourt JA, Batista IS (1981) Magnetic declination control of the equatorial F region dynamo electric field development and spread F. J Geophys Res Space Phys 86:11443-11446

Abdu MA, Bittencourt JA, Batista Inez S (1983) Longitudinal differences in the spread F characteristics. Rev Bras Fis 13(4):647-663

Abdu MA, Sobral JHA, Batista IS, Rios VH, Medina C (1998) Equatorial spread-F occurrence statistics in the American longitudes: diurnal, seasonal and solar cycle variations. Adv Space Res 22:851-854. https://doi.org/10.1016/ S0273-1177(98)00111-2

Abdu MA, Souza JR, Batista IS, Sobral JHA (2003) Equatorial spread F statistics and empirical representation for IRI: a regional model for the Brazilian longitude sector. Adv Space Res 31(3):703-716

Abdu MA, Alam Kherani E, Batista IS, de Paula ER, Fritts DC (2009) Gravity wave influences on plasma instability growth rates based on observations during the Spread F Experiment (SpreadFEx). Ann Geophys 27:2607-2622

Bhaneja P, Earle GD, Bishop RL, Bullett TW, Mabie J, Redmon R (2009) A statistical study of midlatitude spread F at Wallops Island, Visginia. J Geophys Res Space Phys 114:A04301. https://doi.org/10.1029/2008JA013212

Bhaneja P, Earle GD, Bullett TW (2018) Statistical analysis of midlatitude spread F using multi-station digisonde observations. J Atmos Sol Terr Phys 167:146-155. https://doi.org/10.1016/j.jastp.2017.11.016

Booker HG (1979) The role of acoustic gravity waves in the generation of spread-F and ionospheric scintillation. J Atmos Sol Terr Phys 41:501-515. https://doi.org/10.1016/S0273-1177(98)00111-2

Booker HG, Wells HG (1938) Scattering of radio waves by the F-region of ionosphere. J Geophys Res 43:249-256

Bowman GG (1984) A comparison of mid-latitude and equatorial-latitude spread-F characteristics. J Atmos Sol Terr Phys 46(1):65-71

Bowman GG (1990) A review of some recent work on mid-latitude spread-F occurrence as detected by ionosondes. Earth Planets Space 42(2):109138. https://doi.org/10.5636/jgg.42.109

Bowman GG (1994) Mid-latitude spread F occurrence related to geomagnetic activity at preferred local times. Radio Sci 29(3):631-634. https://doi. org/10.1029/94RS00451

Bowman GG (1996) The influence of 10.7-cm solar-flux variations on midlatitude daytime ionospheric disturbance conditions. J Geophys Res 101(A5):10849-10854. https://doi.org/10.1029/95JA03768

Bowman GG (1998) Short-term delays (hours) of ionospheric spread F occurrence at a range of latitudes, following geomagnetic activity. J Geophys Res 103(A6):11627-11634. https://doi.org/10.1029/98JA00630

Bowman GG (2001) A comparison of nighttime TID characteristics between equatorial-ionospheric-anomaly crest and midlatitude regions, related to spread F occurrence. J Geophys Res Space Phys 106(A2):1761-1769. https ://doi.org/10.1029/2000JA900123

Bowman GG, Mortimer IK (2000) Quantitative estimates of relationships between geomagnetic activity and equatorial spread-F as determined by TID occurrence levels. Earth Planets Space 52(6):451-458. https://doi. org/10.1186/BF03352257

Bowman GG, Mortimer IK (2003) Spread-F/sporadic E coupling at Chung-Li, especially for postsunset periods of sunspot maximum years. J Geophys Res Space Phys 108(A4):1148. https://doi.org/10.1029/2002JA009541

Chandra H, Som Sharma, Abdu MA, Batista IS (2003) Spread-F at anomaly crest regions in the Indian and American longitudes. Adv Space Res 31(3):717-727. https://doi.org/10.1016/S0273-1177(03)00034-6

Chen WS, Lee CC, Chu FD, Su SY (2011) Spread F, GPS phase fluctuations, and medium-scale traveling ionospheric disturbances over Wuhan during solar maximum. J Atmos Sol Terr Phys 73:528-533. https://doi. org/10.1016/j/jastp.2010.11.012

Deminov MG, Nepomnyashchaya EV, Sitnov YuS (2005) Regularities of the midlatitude spread F occurrence probability during sunrises and sunsets. Geomagn Aeron 45(4):458-465

Deminov MG, Deminov RG, Nepomnyashchaya EV (2009) Seasonal features in the spread-F probability near midnight over Moscow. Geomagn Aeron 49(5):630-636

Dyson PL, Johnston DL, Scali JL (1995) Observations of gravity waves associated with mid-latitude spread-F. Adv Space Res 16(5):113-116
Fukao S, Ozawa Y, Yokoyama T, Yamamoto M, Tsunoda RT (2004) First observations of the spatial structure of $F$ region 3-m-scale field-aligned irregularities with the Equatorial Atmosphere Radar in Indonesia. J Geophys Res Space Phys 109:A02304. https://doi.org/10.1029/2003JA010096

Hajkowicz LA (2007) Morphology of quantified ionospheric range spread-F over a wide range of midlatitudes in the Australian longitudinal sector. Ann Geophys 25:1125-1130

Hanumath Sastri J (1977) A study of midlatitude spread-F. J Atmos Sol Terr Phys 39:1347-1352

Hoang TL, Abdu MA, MacDougall J, Batista Inez S (2010) Longitudinal differences in the equatorial spread F characteristics between Vietnam and Brazil. Adv Space Res 45:351-360. https://doi.org/10.1016/j. asr.2009.08.019

Huang CS, Kelly MC (1997) Numerical simulations on large-scale ionosphere perturbations in mid-latitude. Acta Geophys Sinica 40:301

Huang CS, Miller CA, Kelley MC (1994) Basic properties and gravity wave initiation of the midlatitude $F$ region instability. Radio Sci 29:395-405

Huang WQ, Xiao Z, Xiao SG, Zhang DH, Hao YQ, Suo YC (2011) Case study of apparent longitudinal differences of spread F occurrence for two midlatitude stations. Radio Sci 46:RS1015. https://doi.org/10.1029/2009R S004327

Igarashi K, Kato H (1993) Solar cycle variations and latitudinal dependence on the mid-latitude spread-F occurrence around Japan. In: The XXIV general assembly. International Union of Radio Science, Kyoto

Kelley MC, Fukao S (1991) Turbulent upwelling of the mid-latitude ionosphere, 2. Theoretical framework. J Geophys Res 96:3747-3754

Kelley MC, Makela JJ, Vlasov MN (2003) Further studies of the Perkins stability during Space Weather Month. J Atoms Sol Terr Phys 65(10):1071-1075

Kherani EA, Abdu MA, de Paula ER, Fritts DC, Sobral JHA, de Meneses FC Jr (2009) The impact of gravity waves rising from convection in the lower atmosphere on the generation and nonlinear evolution of equatorial bubble. Ann Geophys 27:1657-1668

Li GZ, Ning BQ, Abdu MA, Otsuka Yuchi, Yokoyama T, Yamamoto M, Liu LB (2013) Longitudinal characteristics of spread-F backscatter plumes observed with the EAR and Sanya VHF radar in Southeast Asia. J Geophys Res Space Phys 118:6544-6557. https://doi.org/10.1002/igra.50581

Lynn K, Otsuka Y, Shiokawa K (2011) Simultaneous observations at Darwin of equatorial bubbles by ionosonde-based range/time displays and airglow imaging. Geophys Res Lett 38:L23101. https://doi.org/10.1029/2011G L049856

Miller CA (1997) Electrodynamics of midlatitude spread F, 2. A new theory of gravity wave electric fields. J Geophys Res 102:11533-11538

Nicolls MJ, Kelley MC (2005) Strong evidence for gravity wave seeding of an ionospheric plasma instability. Geophys Res Lett 32:L05108. https://doi. org/10.1029/2004GL020737

Niranjan K, Brahmanandam PS, Ramakrishna Rao P, Uma G, Prasad DSVD, Rama Rao PVS (2003) Post midnight spread-F occurrence over Waltair $\left(17.7^{\circ} \mathrm{N}, 83.3^{\circ} \mathrm{E}\right)$ during low and ascending phases of solar activity. Ann Geophys 21:745-750

Ossakow SL (1981) Spread F theories-a review. J Atmos Sol Terr Phys 43:437-452. https://doi.org/10.1016/0021-9169(81)90107-0

Paul KS, Haralambous H, Oikonomou C, Paul A, Belehaki A, loanna T, Kouba D, Buresova D (2018) Multi-station investigation of spread F over Europe during low to high solar activity. J Space Weather Space Clim 8:A27. https ://doi.org/10.1051/swsc/2018006

Perkins FW (1973) Spread F and ionospheric currents. J Geophys Res 78:218-226

Pietralla M, Pezzopane M, Fagundes PR, de Jesus R, Supnithi P, Klinnagm S, Ezquer RG, Cabrera MA (2017) Equinoctial spread-F occurrence at low latitudes in different longitude sectors under moderate and high solar activity. J Atmos Sol Terr Phys 164:149-162. https://doi.org/10.1016/j.jastp 2017.07.007

Rao Rama PVS, Prasad DSVVD, Niranjan K, Uma G, Krishna SG, Venkateswarlu $\mathrm{K}$ (2004) Muti-station studies on spread-F and VHF scintillations in the Indian sector. Terr Atmos Ocean Sci 15:667-681

Sinno K, Kan M (1980) lonospheric scintillation and fluctuation of faraday-rotation caused by spread-F and sporadic-E over Kokubunji, Japan. J Radio Res Lab 27(122):53-77

Wang GJ, Shi JK, Wang X, Shang SP (2007) Seasonal variation of spread-F observed in Hainan. Adv Space Res 41:639-644. https://doi.org/10.1016/j. asr.2007.04.077 
Wang N, Guo LX, Zhao ZW, Ding ZH, Lin LK (2018) Spread-F occurrences and relationships with foF2 and h'F at low- and mid-latitudes in China. Earth Planets Space 70:59. https://doi.org/10.1186/s40623-018-0821-9

Xiao Z, Zhang TH (2001) A theoretical analysis of global characteristics of spread-F. Chin Sci Bull 46:1593-1594

Xiao SG, Xiao Z, Shi JK, Zhang DH, Feng XS (2009) Observational facts in revealing a close relation between acoustic-gravity waves and midlatitude spread-F. J Geophys Res Space Phys 114:A01303. https://doi. org/10.1029/2008JA013747

Xu T, Wu ZS, Hu YL, Wu J, Suo YC, Feng J (2010) Statistical analysis and model of spread F occurrence in China. Sci China Technol Sci 53:1725-1731. https ://doi.org/10.1007/s11431-010-3169-3
Yakoyama T, Otsuka Y, Ogawa T, Yamamoto M, Hysell DL (2008) First three-dimensional simulation of the Perkins instability in the nighttime midlatitude ionosphere. Geophys Res Lett 35:L0301. https://doi. org/10.1029/2007GL032496

Zhou Q, Mathews JD, Du Q, Miller CA (2005) A preliminary investigation of the pseudo-spectral method numerical solution of the Perkins instability equations in the homogeneous TEC case. J Atmos Sol Terr Phys 67:325-335. https://doi.org/10.1016/j.jastp.2004.10.005

\section{Submit your manuscript to a SpringerOpen ${ }^{\circ}$ journal and benefit from:}

- Convenient online submission

- Rigorous peer review

- Open access: articles freely available online

- High visibility within the field

- Retaining the copyright to your article

Submit your next manuscript at $\boldsymbol{\nabla}$ springeropen.com 